\title{
U.S.S. Online Education: Navigating The High Seas Of Large Classes
}

\author{
Jane LeMaster, (E-mail: jlemaster@utpa.edu), University of Texas Pan American
}

\begin{abstract}
Higher education has incorporated technology to the point of having $100 \%$ web-based degree programs composed of classes of geographically dispersed students taught by faculty from different universities that are also geographically dispersed. This kind of flexibility for learning opportunities is well on its way to being a standard option in education. But there are trade-offs and there are problems not yet solved. Increasing numbers of students create difficulties in managing interactions and challenges the quality and rigor that is possible in delivering the course. This paper presents a redesign option to manage the increasing enrollments in an online graduate level management class. As an unexpected consequence of redesign, the level of critical thinking of the students increased.
\end{abstract}

\section{SETTING SAIL}

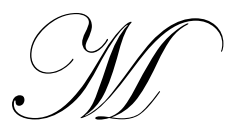

any different events have come together over the past $10-15$ years and created opportunities in higher education that all of us did not have before. Technology, in particular, has become such that anyone, anywhere there is internet access can get into an online class and achieve a degree without ever going to a physical campus. Students no longer need to be within driving distance of the campus, or even within the same time zone to take the same class with each other. Our very mobile society along with increasing globalization and vanishing borders has created more demand for these types of educational opportunities (Friga, et al 2003; Ives \& Jarvenpaa 1996). But with the increasing demand come the associated challenges of large classes, interaction quality, and rigor. This paper presents a case study for how the challenges of managing very large MBA level classes offered $100 \%$ on-line have been redesigned without loosing interaction, quality, or rigor.

I teach two $100 \%$ web-based courses at the graduate level as part of a collaborative on-line MBA program housed in the University of Texas System Telecampus in Austin, Texas. Over the past couple of years my enrollments in these classes have increased significantly reaching 48 students in one class and 76 students in the other. The Telecampus sent out a request for proposals and I was awarded a small grant to redesign one of the courses to address the issue of scale management. The classes I teach are organizational behavior and leadership type classes described by many as "touchy-feely" classes and the first question most will ask is "how can you teach behavior online?" It has been a real learning experience requiring a sea-change in my teaching methodology that has shifted the pedagogical paradigm for both the students and for me. This challenge has taught me how to be more sensitive, how to better interpret what I read, and how to write more clearly. It has taught me patience, tolerance, and not only has it made me more cognitive of my own behaviors, it has also immersed me into a quagmire of human behaviors that change with every class. Simply taking away the visual and verbal cues creates a "whole nuther world" which is also a different paper. This paper explains how small changes in the course format provided for greater efficiency in managing the large numbers of students that resulted in higher quality interactions and without sacrificing rigor.

\section{THE RIPPLE EFFECT}

The primary problem impeding efficient expedition of information throughout the semester was simply the increasing numbers of students enrolling in the classes. Larger and larger classes create a ripple-type effect that requires changes in how a class is conducted. One of the ripples that are inherent in large classes is the ability to manage administrative issues while trying to focus on the academics of the class (Arbaugh 2005; Andriole 1997; 
Easton 2003). When there are 76 students in an online class it is like having 76 classes with one student! As the enrollment numbers increase the ability to create meaningful interactions such that everyone is able to participate becomes another ripple. Developing evaluative methods that are fair for everyone but still manageable for the instructor is yet another ripple. The question becomes how to change (not adjust) the pedagogy to ward off a tidal wave and get maximum interaction without giving up quality of content or loosening the rigor of the course?

\section{WE'RE TAKING ON WATER!}

Online courses carry a myth that implies because there are no walls, there should also be no limits to the number of students in a class. So far the myth has prevailed and the numbers of students enrolling continues to rise. After much reading and many discussions with colleagues, suggestions for how to adjust the course to make it more manageable included changing the testing method to using only multiple choice type exams, with a few short answer questions. This would take much less time to evaluate and would create a much more objective grading system that would decrease the number of questions from students regarding the grading criteria. Most conceptual development types of classes that are teaching the less tangible skills of understanding human behavior in the work environment, leadership, negotiation, communication, and team building require essay type exams in order to determine critical thinking and analytical skills. Graduate students in business will have had the principles and theories of business such that the classes I teach require them to use their ability to apply the principles and theories. Also it is important for graduate level students to be able to explain how and why they think as they do for a particular question and be able to support their answers. Multiple choice questions, therefore are, simply an "easy way out" rather than a solution and in this case do not test the students ability to think critically about a given situation.

Another suggestion from colleagues was made to eliminate the participation/ contribution requirement. This would decrease the amount of time the instructor spent reading postings and making sure everyone is contributing. In a face-to-face class we encourage questions and exchanges of ideas among students that help provide for a richer learning environment. Without interactions among the students, the course would then become simply a correspondence course and this is one of the battles we must fight with regard to explaining the differences in online learning (Friga, et al 2003). Eliminating interaction opportunities also was not a solution to the administrative issues associated with managing high numbers of students in the class.

Most of the administrative issues regard how to navigate the course, how the class is structured, what to do with technical problems, and how to get grades. Sadly most of the students tend not to be independent learners and for many this will be their first online class experience. The experienced and independent learner adapts well to the challenges of the online learning environment, but most require much more attention, structure and detail. Most of the questions and issues that arise, however, are generated at the beginning and at the end of the semester, and those questions at the end of the semester are usually fewer.

\section{BAILING THE BOAT}

\section{Bucket 1}

After much deliberation and thought from changing the entire organization of the course and putting pop-ups throughout, we settled on starting with a tutorial. The first change made to alleviate the administrative demands at the front-end of the course, was the development of an FAQ page for the most commonly asked questions. A few of the questions would take the students to a "viewlet" that was created to show them how to navigate specific screens or buttons. The students could then be referred back to the FAQ page throughout the semester. A tutorial with a START HERE button in bright red was also created as the very first page the students would see when they logged into the class. This gave information about how the course was structured and also took the students to the FAQ page. It gave information about exams, about the discussion boards, and about the team projects. All of these additions allowed the students to be referred back to the specific tutorials for the information they were seeking. The instructional designers assigned to help develop my ideas for redesigning the course were very helpful in pointing out unclear messages, mixed signals, and verbiage that simply did not make sense. 
We know that part of what differentiates face-to-face and online classes from correspondence courses are the interactions but unlike face-to-face classes, body language simply does not translate well in the online environment. What we have learned from the literature is that student-to-student interactions are the most effective for learning. But similar to the face-to-face class, the more students there are the easier it is for other students to fade into the background or create an excuse for missing information. Also, the greater the number of students, the greater the number of postings and also like face-to-face classes, there are always those who will capitalize on a captive audience and be the first to speak and often say more than is necessary (Arbaugh 2005; Andriole 1997; Alavi et al 1997; Benbunan-Fich et al 2003; Borthick \& Jones 2000; Hiltz \& Turoff 2002; Javenpaa \& Leidner 1999; Swan 2002).

\section{Bucket 2}

In an effort to help prevent students from fading into the background, and to help alleviate the numbers of postings, two discussion boards were created; one for the entire class (called the Public Board) and the other for individual teams of students (called the Private Board). The teams were required to discuss the weekly topics among themselves in their Private Board and then assign a representative to bring the team's consensus to the Public Board. The outcome from this redesign feature was two-fold: first, it accomplished the goals of not losing students to the background, and it gave all students the opportunity to contribute to the class. The second outcome, although not expected, created a turning point for both the instructor and the students with regard to the quality of learning from the course. The requirement for the students to discuss specific topics within their small groups allowed them to "talk" through the less important issues and ask the less obvious, more thought provoking questions such that by the time a representative posted the team's comments, the comments took the class discussion to a different level (Respa 2005). The postings on the Public Board after creating the Private Boards were at a higher level of contribution and critical thinking than they had been before adding the Private Boards.

Within the team discussions, all of the members (usually 4 to 8 students) on each team were able to become personally engaged in reading, managing, and making meaningful contributions to the discussions. The teams were homogeneous from the perspective of everyone on each team usually being from a different university and different geographic location. Everyone had different backgrounds in terms of their jobs and work experiences, their families, educational maturity and life-style. But for these same reasons the dynamics within the groups were very different. Each team developed their own personality. One team changed its name from Team 7 to the Magnificent 7 and the discussions within the team were always very positive. All members identified with the team and there did not seem to be one "designated" leader within the group. Another team was so dysfunctional two members asked to be moved to a different team. Because the change was mid-way in the semester, both teams suffered. The new team had already established the routines and assignments and even though the team welcomed the new members, the new members were never able to "fit-in" completely.

All teams had the same objective which was to complete the course with the best grade they could. Some were more career driven, seeing the course as just another check-mark off the degree plan, while others were mission driven, seeing the course as an opportunity and good learning experience. It was necessary, therefore, for each team to determine the strengths and weaknesses of each member as well as each member's view of the course.

\section{Bucket 3}

As noted earlier, graduate level organizational behavior and leadership and change classes are not conducive to multiple choice type exams so changing the exams from essay to multiple choice was simply not an option for either managing the masses or evaluating learning at the graduate level. Creating teams of students provided for several important changes that enhanced both the efficiency and the learning environment of the class. Having teams allowed for the development of team projects that became part of the performance evaluation. Having teams provided the opportunity for peer evaluations that helped in the evaluation of participation and contribution of each student, and having teams provided for more meaningful postings that everyone was able to read and comprehend without getting overwhelmed by the numbers of postings. But we still need to be able to evaluate individual performance in a meaningful and appropriate way for graduate level learning. The real learning experience for the students happened within the teams (Arbaugh 2005; Chidambaram 1996; Coppola et al 2002; Jarvenpaa\& Leidner 1999). The team 
development followed the literature regarding how groups of people must go through stages that allow them to determine their own positions within the group before they are able to perform as a team. And as is common, leaders emerged within each of the student teams. Issues of accountability and responsibility arose and in two cases students requested and were allowed to be reassigned to a different team selected by the instructor. Because the team membership consisted of only a few people instead of the many tens of people in the whole class, it was difficult for any single member not to contribute to the team. A few teams created very structured organizations assigning each task to specific individuals, setting up chat rooms, and scheduling assignments with due dates. Some teams requested additional private discussion boards organized according to the weeks of the semester. They then targeted their weekly private discussions to the appropriate discussion board week.

\section{Bucket 4}

Like face-to-face classes, the inherent problem of testing where students from the current semester gain access to questions from previous semesters, the online environment is not different and the testing issue is a real challenge for the online instructor. Graduate students in management should be able to demonstrate their knowledge of the principles and theories by applying that knowledge to actual problems. To test appropriate graduate level comprehension, for one class a list of contemporary articles from current periodicals illustrating the information from the class was given to the students at least one week before an exam. Essay-type questions were drawn from the articles and the students were asked to answer the questions applying what had been learned in the class and using the support materials from the course. For the other course classic films that illustrate leadership principles and theories were used and questions were asked that required the students to draw from the course materials to support their answers to the questions. This testing methodology adds to the workload of the instructor as the class size increases because the exams must then be graded.

\section{Bucket 5}

One of the biggest problems with evaluating graduate level work for organizational behavior, leadership and change classes is the amount of subjectivity that must be made in evaluating student learning. The instructor is very closely engaged with the students through the discussion boards and this gives the instructor a very good sense of the student's seriousness, their commitment and responsibility to the class. This close engagement by the instructor often invites discontent regarding the evaluation of students' work. Given the testing methodology, theoretically every student could have a different yet correct answer. So there had to be a way of introducing more objectivity into the grading process. My teaching philosophy includes the importance of presentation and process. It is important that students understand that how they say what they say is as important as what they actually say. This is never more evident than in the online environment when someone will post a comment that another student interprets differently than was intended and the originator of the comment must apologize or restate the comment more clearly. As a consequence, half the grade for each exam is applied to process (presentation, format, following instructions) and half is applied to content (how the question is answered and supported). The content grade is further divided such that half the content grade is the sources used to support what is said. This revised evaluation method leaves only $25 \%$ of the exam grade to a subjective evaluation of what is actually written as an answer to the question.

Even though teaching assistants have often been assigned to help manage the online classes, their lack of expertise has been more of a hindrance than a help, and in most cases the teaching assistants are master's level students themselves. Changing the evaluation format has created more efficient use of a teaching assistant to help evaluate the objective parts of the exams.

Because we know we must have participation from the students in order to have meaningful student-tostudent interactions, peer evaluations were developed and administered after each of the team projects. Evaluation questions provided information regarding which team members were contributing to the team and which were not contributing to the team. The peer evaluations represented $50 \%$ of the participation/contribution grade with the remaining 50\% a subjective evaluation from the instructor which was based on whether the student logged in to the class regularly and if the students were posting meaningful comments saying more than "I agree". Most teams were 
very self-regulating demanding much from each other which gave credence to the peer evaluations. Each team project, each exam, and the participation/contribution grade each carried a weight of $20 \%$.

\section{THE SHORE IS IN SIGHT}

The variety in the evaluative methods allowed for the different strengths of each student - no one requirement in the class would "sink" the student. The performance outcome was as expected and not unlike a faceto-face class. There were over-achievers, under-achievers, and mid-range achievers. Observations of the types of interactions and the activity on the Private Boards revealed that the over-achiever students were those who were comfortable with the open format of the class, or at least accepting and willing to adapt. Those less comfortable with the open format and unwilling to adapt tended to be the under-achievers. Good things happened both within and between teams. For example, when the less independent learners would post a question in the Public Board that had been answered previously, either in a post or in the tutorial, another student would quickly respond rather than allow the instructor to respond. This attitude of taking care of each other was prevalent in both the Public Board and the Private Board. Part of the reason may be a result of the "team" environment or simply the more independent learnercentered environment that is created with on-line delivery.

There is anecdotal evidence supporting the use of teams to alleviate the enormous numbers of postings that can be created with large numbers of students. As an example, in one class the average number of postings per week over 12 weeks in the Public board was 49 while the average number of postings for the ten teams for the same period was 343 on the Private boards. In most cases the students appreciate the need and opportunity to have teams, but there are always those who object greatly to having to work with other students and be graded the same knowing not everyone contributes the same. Some students have actually made friends and stayed in contact with team mates, while others hope never to be on another team.

There is also anecdotal evidence that learning takes place when students are allowed to interact and exchange ideas. Comments have ranged from "this is the best team I have ever worked in" to thanking me for the opportunity for them to work with such a great team. Because the first week of my semester is set aside for all the students to familiarize themselves with the structure of the course and to make sure all the technology is working properly, I create a discussion forum on the public board and ask a provocative question to which everyone is asked to respond. The most successful question has been: "Are leaders made or born?" Surprisingly, this question received so many comments that the forum was left open for longer than intended. Other provocative questions that create good discussion include: "Is leadership an art or a science?" and "Who make better managers, men or women?"

The self-regulation that takes place within the teams to make sure the team meets the course requirements is not evidenced in the public discussion board. In the private discussion boards, the students are very straight-forward, more relaxed, willing to write most anything and about any topic. In the public discussion board the exchanges are much more formal and more serious. There is also a sense of competitiveness in the private board that interestingly is not evident in the public board. This competitiveness surrounds the team wanting to out-perform the other teams. There was often one team member needing to "win" their point, and only one instance of the inability to concede.

\section{THE DOCK IS NEAR}

Teaching a large section of students at the graduate level in such a way that we promote engagement of all students and help them incorporate the course materials into their daily lives was the redesign challenge. The modifications made to the classes I teach as a result of the increasingly larger enrollments reflect the model we use in academe. In the model of the academy, faculty at all the different colleges and universities work out a problem through collaboration or independently and then bring the results to a public forum like a conference or journal publication so everyone can share in the knowledge. Placing students in teams is not a new or innovative idea, but setting up team discussion boards with the instruction to deliberate a topic and then prepare a consensus that must be presented to the class as a whole is at the least creative. Following the model from academe as the analogy, the teams of students exchanging ideas on their private discussion boards represent the faculty, and the team consensus posted to 
the public board represents the conference or journal publication. This methodology has worked for the academy for many years and is also working for the online class environment.

The intellectual inquiry of the academic model can be painful because it requires analytical and critical thinking and it requires presenting your carefully thought-out and presumably well supported results to a body of your peers who may disagree and question your efforts. This also happens as a result of the redesign of my classes.

The student teams come to realize fairly quickly that they need to do a pretty thorough job of evaluating and/or researching the assigned topic before they place their names on the public board. They also realize they must be able to support their position with more than "We think". This is what has created the richness of the learning environment and the students have taken this responsibility on themselves. They are becoming teams of learners developing leadership skills, communication skills, negotiation skills, and team-building skills.

\section{BATTEN THE HATCHES AND WEIGH THE ANCHOR}

Increasing enrollments cannot be viewed as a problem! We need to talk about the increasing enrollments as challenges and opportunities. With regard to meeting the challenge I adapted my pedagogical approach and made teams of students an essential element of the course format. An easy to use tutorial was created that gave step-by-step information for navigating the course, answered most commonly asked questions, and was made the starting point for the course. A model was developed for evaluation of student works that is both objective and subjective and the use of teams has provided more efficient management of the interactions between and among students.

The student drop-out rate is higher for the on-line classes than for the face-to-face classes by a significant amount and it is not known if this is a function of the course format, or simply the on-line environment. Unlike a face-to-face class, it is difficult to know all that is not being written, or what is behind some of what is written. In the face-to-face class the verbal or visual cues can tell a lot about the potential retention success for a student. Take away those cues and it will take a very astute instructor to pick up potential drop outs. I will regularly check to see how often everyone is logging into the class and for those who have not been regular I will send a personal email and make sure everything is going well. I have on several occasions found the personal concern to be the difference between the students staying or not staying in the course. Usually, those who do not work well with other people or who are unable to find ways to manage their time and the demands of the class will withdraw from the class. Others who are unable to "get along" within the team or do not contribute what the team considers a fair share, will often also drop the course.

There is probably much that can be done towards alternative, more innovative ways of evaluating performance as the enrollment numbers continue to rise. Having team projects and group evaluations decrease the amount of grading that must be done, but there must also be at least an equal amount of evaluation of individual performance as well. Peer Evaluations are a good way to get individual performance, but can be unfairly biased if there are severe personality conflicts. Creating exams that provide a scenario with multi-level answers that require the student to think through the answer options carefully could help alleviate the grading demands from essay questions. This format would not allow the student to come up with the solutions, but rather choose from a variety of solutions. The objective is not so much the solution, but rather how the student defends the solution to the question. Having other than essay type questions seems to dilute the critical thinking requirement greatly.

Without doubt using teams as a pedagogical tool and an essential element of the evaluation process is sound, particularly given that industry has noted most business school graduates lack the intangible skills like leadership, communication, negotiation, and team building. Placing groups of students together from geographically dispersed universities and asking them to perform projects for which they will all receive the same grade requires them to pull together their individual strengths and set aside their differences to be successful as a team. The skills the students develop in the process are leadership, better communication, negotiation, and team building. 
When I decided on a career change from industry to higher education I was asked if I was sure because in higher education we "count our successes in ones and twos". But if we accept that imitation is the sincerest form of flattery, I have a success to share in the form of an email that was sent to me from a student:

- $\quad$ I am not sure if you remember me ... but I took your Management and Organizational Behavior course. I have utilized your bulletin board set up for the RN-BSN Patho course that I teach and it has worked out well. The students were a bit confused at first (they always are) but I think they got into the swing of it after 2-3 weeks. I appreciate you letting me model my bulletin board after yours.

- $\quad$ I also thought about something else that I would like to implement in my courses ... We always hear how one member doesn't perform and that group activities foster the quiet student. In your course, you had the team evaluate the team. Could you remind me of the questions that you used and your strategy for grading peer evaluations? I am also thinking of implementing one activity or case study that the student must do individually similar to your exams that will give an individual grade.

- I am so glad I took your course. As you can tell I have also learned DE course management from you. I wish other faculty would take the time to take an on-line course so that they too could learn from their colleagues. One of the courses I have this semester is absolutely awful, I feel like I am doing a bunch of busy work rather than learning the material. That instructor could learn a lot from you.

- I hope that you don't mind that I am using your course as a model for mine. I just really liked your setup.

This is what makes all the time, energy, and frustration of finding solutions for the online delivery problems worthwhile. From the student evaluations of the course most of us always get complaints from those who did not like the format, their fellow team members, or the demands from the class and these complaints are typically in the form of our teaching abilities. But we also get those sincerest of comments like "I really enjoyed this class", "I really learned a lot", "and the tests were hard but fair", "I usually don't like working in teams, but this was a good one", and my alltime favorite, "Dr. LeMaster is a really good professor". We will continue to work on developing better ways of teaching on-line without sacrificing the student-to-student interactions, the quality of the course learning environment, or the rigor of the evaluation methods, and we will use the landmarks from the comments questioning my teaching ability to make necessary course corrections.

\section{FUTURE VOYAGES}

Moving from student/learner-centered to team-centered learning may be the next paradigm. Certainly there is a need to refine the tools we use to develop critical thinking and analytical skills and certainly we need to address the concerns of the current and future employers of our graduates as well as the changing demands in graduate education for the $21^{\text {st }}$ century.

Imagine a voyage with a semester long project that requires teams of geographically dispersed students to run a business and make all the necessary decisions associated with the everyday management of the organization. These teams of students will compete for market share with other teams of students whose professors are utilizing the same project. The project will tie not only the functional area aspects of the business together, but it will provide a handson learning environment for decision-making with real outcomes for their companies. The teams could be evaluated at the end of the semester on performance of the firm over time, on the actual decisions that were made, on presentations, and 360 personnel performance reviews. This voyage has already been made in the face-to-face environment. Perhaps it is time to put it in the online environment. 


\section{REFERENCES}

1. Alavi, M, Yoo, Y. \& Vogel, D.R. (1997) Using information technology to add value to management education Academy of Management Journal, 40: 1310-1333.

2. Andriole, S.J. (1997) Requirement-driven ALN course design, development, delivery \& evaluation: Journal of Asynchronous Learning Networks 1(2): http://www.aln.org/publications/jaln/index.asp

3. Arbaugh, J.B. (2005) How much does 'Subject Matter' matter? A study of disciplinary effects in on-line MBA courses Academy of Management Learning \& Education 4(1): 57-73.

4. Arbaugh, J.B. (2005) Is there an optimal design for on-line MBA courses? Academy of Management Learning \& Education 4(2):135-149.

5. Benbunan-Fich, R, Hiltz, S.R. \& Turoff, M (2003) A comparative content analysis of face-to-face vs. asynchronous group decision making Decision Support Systems 34(4): 457-469.

6. Borthick, A.F. \& Jones, D.R. (2000) The motivation for collaborative discovery learning online and its application in an information systems assurance course: Issues in Accounting Education 15(2): 181-210.

7. Easton, S.S. (2003) Clarifying the instructor's role in online distance learning Communication Education 52:87-105.

8. Friga, P.N, Bettis, R.A., Sullivan, R.S. (2003) Changes in graduate management education and new business school strategies for the $21^{\text {st }}$ century Academy of Management Learning and Education 2(3): 233-249.

9. Hiltz, S.R. \& Turoff, M (2002) What makes learning networks effective? Communications of the ACM 45(4):56-59.

10. Ives, B \& Jarvenpaa, S.L. (1996) Will the internet revolutionize business education and research? Sloan Management Review 37(3):33-41.

11. Jarvenpaa, S.L. \& Leidner, D.E. (1999) Communication and trust in global virtual teams Organization Science 10:791-815.

12. Swan, K (2002) Building learning communities in online courses: The importance of interaction Education Communication and Information 2(1): 23-49. 